\title{
Designing for Diverse Stakeholder Engagement in Resource-Intensive Practices
}

\author{
Hanna Hasselqvist \\ KTH Royal Institute of Technology \\ Stockholm, Sweden \\ hannaha@kth.se
}

\author{
Elina Eriksson \\ KTH Royal Institute of Technology \\ Stockholm, Sweden \\ elina@kth.se
}

\begin{abstract}
Despite many contributions to Sustainable HCI stressing the importance of "moving beyond the individual", a majority of HCI work is still targeted mainly at consumers or resource users. However, many stakeholders influence resource use and including such stakeholders in design work can open up new design opportunities for supporting sustainable practices. In this paper, we present results from a longitudinal study of practices related to energy improvement work in housing cooperatives. During the study, we discovered new opportunities for interactive technologies to support this work when we involved various stakeholders other than housing cooperatives. In addition, we discuss more general implications for design aiming to support diverse stakeholder engagement in practices related to resource use: which stakeholders and practices to include, temporal aspects of engagement, and opportunities for supporting shared responsibility for resource use.
\end{abstract}

\section{Author Keywords}

Sustainable HCI; resource use; resource-intensive practices; energy; stakeholders; design.

\section{ACM Classification Keywords}

H.5.m. Information interfaces and presentation (e.g., HCI): Miscellaneous

\section{INTRODUCTION}

In Sustainable HCI, one approach to environmental sustainability has been to explore how the use of interactive systems can support decreased use of resources (energy or materials), for example in terms of reduced energy use in homes, energy efficient transportation, or reduction of food waste. These systems have often focused on providing information and triggering motivation for individual users to make more sustainable choices. However, over the past years this focus has also been criticised for, among other things, only promoting incremental change [5] and for not

\footnotetext{
Permission to make digital or hard copies of part or all of this work for personal or classroom use is granted without fee provided that copies are not made or distributed for profit or commercial advantage and that copies bear this notice and the full citation on the first page. Copyrights for thirdparty components of this work must be honored. For all other uses, contact the Owner/Author.
}

NordiCHI'18, September 29-October 3, 2018, Oslo, Norway

(C) 2018 Copyright is held by the owner/author(s).

ACM ISBN 978-1-4503-6437-9/18/09.

https://doi.org/10.1145/3240167.3240193

This work is licensed under a Creative Commons Attribution International 4.0 License. considering the social practices that are the primary reason for why resources are used [38]. Furthermore, the focus on individual behaviours in resource use have resulted in persuasive technologies and other measures to decrease resource use that put the responsibility of managing resources (and the blame for failing to do so) solely on the resource users $[9,32,36]$. When interaction design efforts are targeted only on users with roles such as householders, car users or energy consumers, the idea of consumer responsibility is reinforced. While alternative approaches have been adopted, particularly in terms of exploring practices from a Sustainable HCI perspective [27], there are still few examples of designs of interactive systems that target stakeholders other than direct resource users. Consequently, we know little about the design opportunities and challenges that come with such an approach.

Although resource users are important for how resourceintensive practices evolve over time, there can be many other contributors to a practice [33]. Energy users, for example, are not alone in forming future energy practices: governments, energy providers, architects and media are a few examples of stakeholders that influence practices related to energy use in homes. While all contributors to a practice are important, some stakeholders have more power than others to influence a practice in a sustainable direction [31]. It has been suggested that HCI research should explore how citizens can be empowered to put pressure on stakeholders with a greater influence on for example energy related practices, but also that research should engage directly with decision makers and promote collaboration between stakeholders [28].

This paper contributes to an increased understanding of how perspectives and practices of diverse stakeholders can be considered in Sustainable HCI and design work. First, we present results from a longitudinal study of practices related to energy improvement work in housing cooperatives in a Swedish context. In this study, we have shifted from a focus mainly on energy users (i.e., housing cooperatives) to actively including additional stakeholders that influence energy use in housing cooperatives. We analyse how this change in focus opened up new design opportunities for interactive systems to support energy improvements, and how it influenced particular design considerations compared to our initial design work targeting housing cooperatives. Finally, we articulate and discuss more general implications for design aiming to 
support diverse stakeholder engagement in practices related to resource use.

\section{STAKEHOLDER ENGAGEMENT IN SUSTAINABLE HCI}

Sustainable HCI covers many issues and aspects of sustainability. In this paper we focus on the use of interactive technologies to support more sustainable practices, i.e. sustainability through design [23], with a particular focus on support for sustainable resource use. One major critique of this type of research has previously been that the studies and explored systems mainly targeted individual consumers [5,8]. People's behaviour was often regarded as the problem to be solved, and the solutions included ways for resource users to understand their behaviour and its consequences [5]. Despite this critique, little appears to have changed in how stakeholders are approached in Sustainable HCI, and more effort needs to be put into identifying the "complex network of stakeholders" influencing sustainable practices [29].

Although most Sustainable HCI work targets resource users or consumers, there are examples of recent work in Sustainable HCI explicitly targeting other types of stakeholders. One strand of research investigates interaction between energy professionals and resource users. In domestic settings, these stakeholders include energy advisors supporting people in fuel poverty $[11,12]$, where energy sensor data was found to be useful in establishing relationships between advisors and households, and energy auditors using thermal data as a communication tool with homeowners [25]. In office buildings, interactive systems and energy data have been studied as interfaces between facilities managers and office occupants. Such technology may support dialogue between office staff and energy decision makers [3], negotiations of thermal comfort in relation to energy use [6], and detection of problems related to thermal comfort and the energy systems [2]. However, while increased access to energy data in office buildings can support facilities management in many ways, it also comes with risks of reinforcing power imbalances between facilities managers and office occupants [10].

Another example of studies not targeted only at resource users are studies of interactive systems where the users can take different roles. This includes peer service technologies [4], where the system users are both people in need of products or services and people who can provide these products or services. Another example is technologies enabling individuals to act as novice energy auditors and explore not only their own energy use but also energy use at workplaces and in public spaces [26].

In addition to focussing on users of interactive systems, it may be useful to consider the perspectives of stakeholders providing interactive systems related to sustainability. The previously mentioned peer service study [4] compares the design intentions of system providers' to the motivations of users of peer service systems. They found that for environmental aspects, design intentions and user motivations were not always aligned. Another study explores how managers or owners of crowdfunding platforms with sustainability focus aim to engage people in these topics [22]. As system providers, these stakeholders potentially have a strong influence on resource use and, according to the studies, they clearly express ambitions to contribute to a more sustainable use of resources.

Finally, there are studies aiming to understand or facilitate communities of stakeholders engaged in sustainable resource use. This includes understanding issues and practices of energy communities [14], supporting citizens in monitoring air pollution from a local fuel plant [18], and a food sharing community, including consumers, farmers, retailers and a food sharing association, aiming to reduce food waste with the help of an online platform [13].

Among studies that focus on resource users and their practices, some studies stress that future work should consider additional stakeholders. For example, to address energy issues it is suggested that HCI should promote collaborations between decision makers (with high power to influence practices related to energy use) and citizens (who may feel unable to influence energy use) [28], and to provide support for correct waste recycling it may be useful to engage recycling companies and policy makers [21]. Furthermore, workplaces and children's sports teams are identified as interesting stakeholders when supporting sustainable transportation practices [17], and schools, supermarkets and restaurants are suggested to be important for sustainable food practices [7]. Collaborating with stakeholders such as educators, companies and policy makers can also be a way for Sustainable HCI to diversify how change is approached in relation to sustainable practices [19].

As much other Sustainable HCI research, our study had a similar starting point of exploring practices of resource users. However, during the course of the study we included additional stakeholders, which influenced design opportunities and challenges. By articulating and discussing design implications of moving from a resource user perspective to including additional stakeholders, we aim to support more research to "move beyond the individual".

\section{RESEARCH SETTING}

Our work with housing cooperatives spans over four years, and the research focus and explored design goals have evolved over this time (see Figure 1). In this paper, we focus on the most recent work: the influence of various stakeholders on energy improvement work and how stakeholder engagement may be supported by interactive systems and open energy data. The results from the previous steps are, however, important for understanding the shifts in focus and the design opportunities presented in the paper. We therefore provide a background of the work before presenting the most recent parts of the study. 


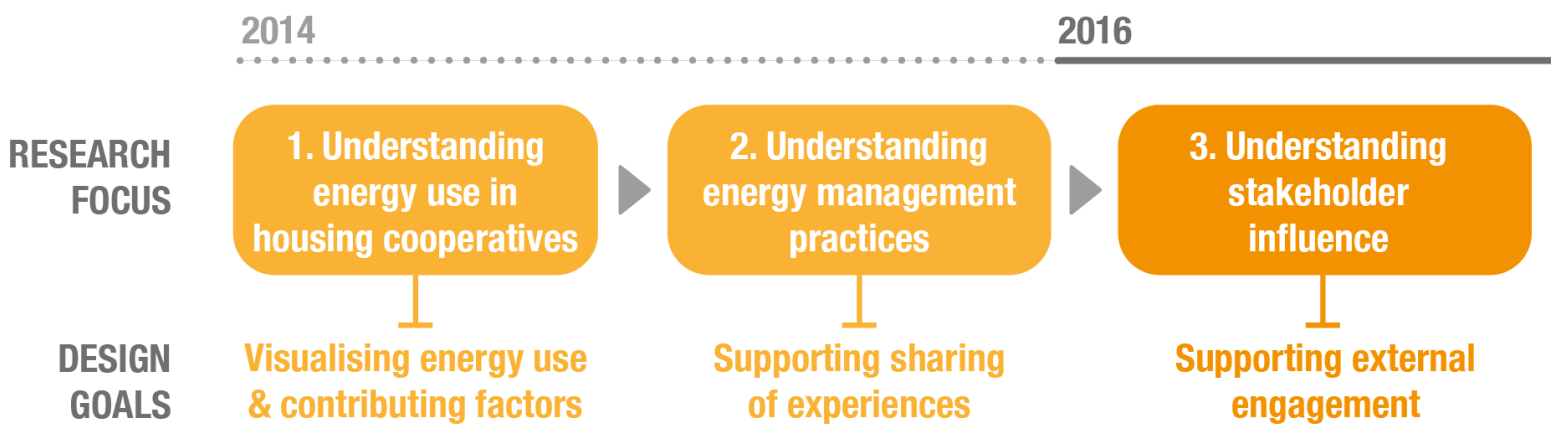

Figure 1. Overview of changes in research focus and design goals during our study of energy in housing cooperatives.

\section{Understanding Energy Use}

Energy use in buildings, and opportunities for reducing the environmental impact of energy use, depend on factors such as type of building, local climate, energy infrastructures, energy regulations, and cultural context. Our study concerns energy use in buildings owned by housing cooperatives in Sweden, and a first focus of the study was to understand energy use in this specific context (step 1 in Figure 1).

People who buy an apartment in Sweden have to become a member of the building's housing cooperative. Energy in this setting can be divided into household electricity, heating, hot water, and electricity used in the shared facilities. Heating and hot water, provided through district heating, and facilities electricity are typically shared costs over all apartments, where heating and hot water have the overall largest share of the energy costs. Initially the intention of the project was to engage directly with the households and their energy use. However, individual households have rather little power to influence the overall energy use, in particular the heating, since the cooperatives' energy systems mainly are managed on a building level and structural improvements of the buildings need to be managed collectively. Hence, we focussed our research and intervention on collective energy improvement work in housing cooperatives.

\section{Understanding Energy Management Practices}

Energy management and energy improvement work in housing cooperatives is closely linked to general housing cooperative management practices, and a second focus of our study was to explore these practices (step 2 in Figure 1). Housing cooperatives annually elect a board among its members that makes decisions on behalf of the cooperative. The board is also in charge of the cooperative's financial management and maintenance of the buildings. Some cooperatives have a board member who is in charge specifically of energy issues, often called energy manager. Many of the energy managers we worked with did not know much about energy management, and their practices are very different from professional energy management practices. In our previous work [16] we describe how we supported them with a tool, an energy app with open energy data, for exploring energy use and sharing experiences of energy improvement actions (see Figure 2). The open energy data include monthly and yearly data for the cooperatives' total use of electricity and district heating, which is automatically collected from the energy providers (with the cooperatives' permission). The data is open to all users of the app and housing cooperatives can annotate their own energy data with information about energy improvement actions they have taken. To provide a context for the data, the housing cooperatives also add information about themselves, such as number of apartments and type of ventilation system in the building.

The design of the energy app was based on the work of the two first steps of our study shown in Figure 1. The energy app is still in use, although in an updated version, two years after it was launched, with new cooperatives joining every now and then. In our previous work, we learned that the users appreciate the app for giving them access to other cooperatives' experiences. However, when it comes to sharing experiences of energy actions taken by their own cooperative there has been little activity other than when prompted by us. Different practices compete for people's time [34], and energy managers in housing cooperatives are involved in many other practices that may concern more pressing issues. Adding to the design challenges is the fact that energy management, as well as other board responsibilities, is volunteer work that people often engage

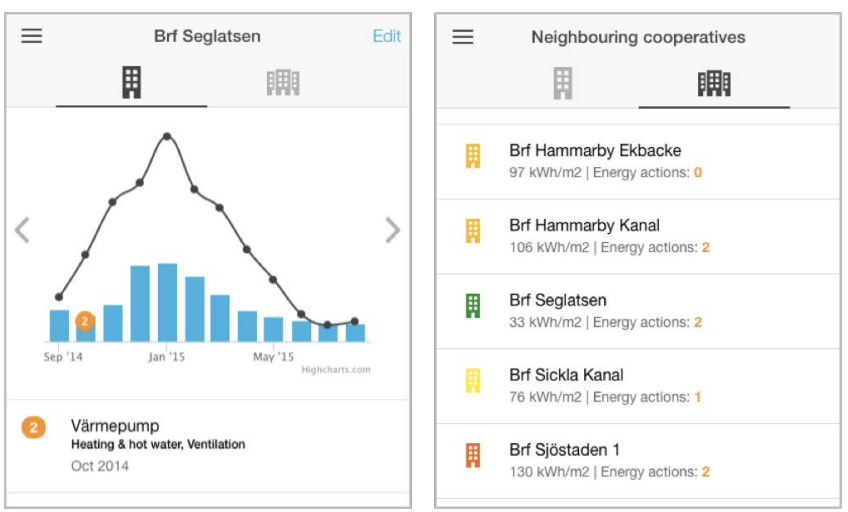

Figure 2. Screenshots from our housing cooperative energy app with features for cooperatives to see their own and others' energy use, to follow up on energy improvement actions and to share experience between cooperatives. 
in only for a short time. Hence, over the course of a few years a cooperative can have several generations of energy managers. This may mean that a cooperative that once signed up for the energy app through a previous energy manager could be completely unaware of the existence of the app today.

Although the design of the energy app certainly could be further improved for the current target group, we doubted whether that would be enough to provide long-term support for housing cooperative energy management. And having a long-term perspective is crucial, since energy improvement work is an ongoing process where one single action to reduce energy use can span over generations of energy managers. To address this challenge, we decided to expand our research beyond the housing cooperatives. We wanted to explore how other stakeholders influence housing cooperative energy management and if there were opportunities in designing interactive systems to support their engagement in housing cooperative energy management (step 3 in Figure 1).

\section{METHOD}

To explore possibilities to design for stakeholder engagement, we contacted companies and organisations that influence, or could potentially influence, housing cooperative energy management practices. In addition, after the energy app was launched, we were approached by stakeholders that heard about the project and were interested in collaborating or learning more about it. During 2016 and 2017, in parallel with continued work directly with housing cooperatives, we met with: a Local Energy Initiative ${ }^{1}$, municipal Energy Advisors in a Swedish city, a national Housing Cooperative Organisation, two Building Management Companies (BM1 and BM2), a Maintenance Planning Consultancy, and an Energy Provider for district heating.

We initially met separately with each of the 7 stakeholders, with one or two representatives from the stakeholder in each meeting. The meetings lasted in general 1-2 hours and were carried out face to face, mostly at the stakeholder's premises. In the meetings we introduced our project, asked questions about the stakeholder's work with housing cooperatives and discussed future opportunities. The energy app designed for housing cooperatives (see Figure 2) was used to trigger and support discussions both of the stakeholders' current relations to housing cooperative energy management and of ideas for how interactive systems and open energy data can support collaborations with housing cooperatives. In addition, we organised a follow-up workshop (2 hours) with the Housing Cooperative Organisation and the Energy Advisors, to

1 The Local Energy Initiative was formed in a new city district with high sustainability ambitions, where the housing cooperatives were concerned by the buildings' surprisingly poor energy performance. explore in greater detail different types of energy improvement actions relevant for housing cooperatives and challenges related to energy comparisons. In connection to these meetings, we also started collaborating with the Local Energy Initiative and the Housing Cooperative Organisation. This led to additional meetings that further deepened our understanding of their roles in energy management.

The meetings were documented through detailed notes and/or audio recordings. This was complemented by information shared via emails, presentations and handouts. In the results, accounts based on the documentation are presented and direct quotes are included where possible. The documentation was analysed to identify: (1) types of stakeholder engagement in housing cooperative energy management practices, and challenges or tensions in this engagement; and (2) design opportunities for using open energy data and related services to support stakeholder engagement. The design opportunities were further developed and compared to our design of the energy app.

\section{STAKEHOLDER ENGAGEMENT IN HOUSING COOPERATIVE ENERGY MANAGEMENT}

In this section we present different types of stakeholder engagement directly or indirectly influencing energy management and energy improvement work in housing cooperatives (see Figure 3 for an overview). These include energy advice, building management services, long-term building maintenance, and new forms of services and support.

\section{Energy Advice}

A common form of support provided to housing cooperatives is energy advice. For independent advice on how to reduce energy use, housing cooperatives can contact the municipal energy advice service that is provided free of charge by almost all municipalities in Sweden. However, it is not only municipal energy advisors that provide energy advice for housing cooperatives. The Energy Provider, whose core business is production and distribution of district heating, both gives advice to cooperatives individually and organises energy meetings for groups of cooperatives. Similarly, the Housing Cooperative Organisation, which offers a number of services for their members, organises energy meetings in different local groups and provides general energy advice on their website and in their member magazine.

\section{Lack of Trust in Stakeholders}

Unfortunately, advice is not enough for energy improvements to be realised, not even when the improvements are cheap to implement and the pay-off time is short. Both the Energy Advisors and the Energy Provider reported that often when they revisit or follow up with housing cooperatives one or two years after providing advice, few energy improvements have been implemented. The Energy Advisors had investigated why, and according to their experiences common reasons were that the board 


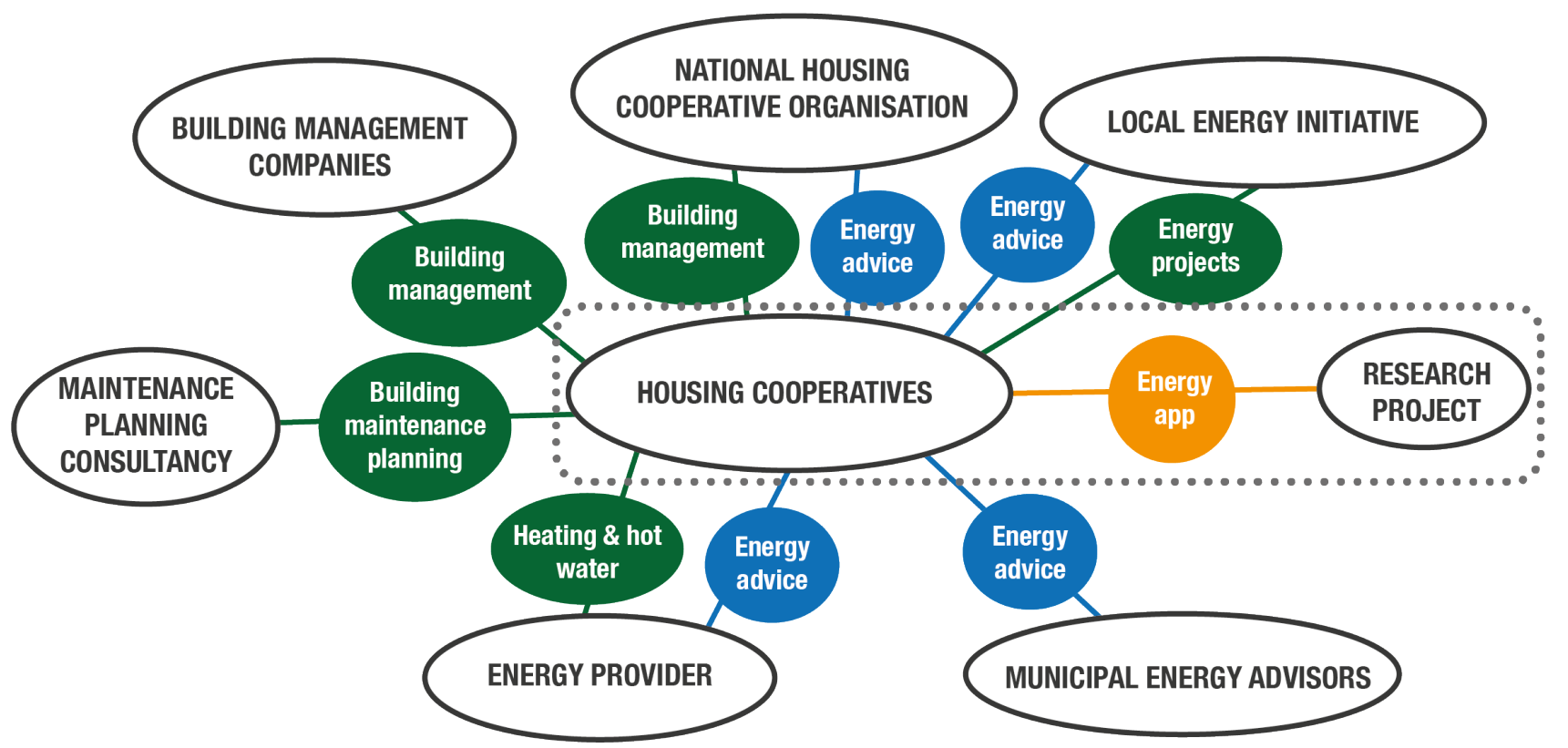

Figure 3. Stakeholders and their main interactions with housing cooperatives and influences on energy management practices. Some activities or services have a direct impact on energy use (green) while others may indirectly affect energy use (blue). The dotted area shows our initial research focus on supporting housing cooperatives, corresponding to step 1 and 2 in Figure 1.

members had changed or that they had questions regarding how to implement the advice. This includes questions such as how to "get what you want" and how to "know that you're not being cheated". Since housing cooperatives are run by people who may not know much about energy, the Energy Provider described housing cooperatives as: "a dream market for companies with false intentions."

Housing cooperatives' difficulties in judging advice and offers from different stakeholders also affect the trust in these stakeholders, although the trust was believed to vary between different stakeholders. The Energy Advisors experienced that many people sought their advice because it was perceived as objective, but they had heard people being sceptical towards other stakeholders:

"...people have very low trust in contractors [e.g. companies involved in renovations and implementation of energy improvements]. One almost assumes that one will be cheated. [...] In my experience, many of the people I meet with are very, very skeptical towards [name of an energy company, which provides energy advice] and say that they will only rip us off."

For the case of energy companies, there is indeed a contradiction in the ambition to contribute to reduced energy use when they at the same time make more money the more energy their customers use. Considering the current business models of energy providers, the intent of their energy advice has also been questioned by housing cooperatives we have met.

\section{Uncertainty of Energy Advice}

Furthermore, what is good advice is not necessarily straightforward as even energy experts, without vested interests, may disagree. In the workshop where we discussed which energy actions are suitable for housing cooperatives, the energy expert from the Housing Cooperative Organisation and the energy expert from the Energy Advisors disagreed on whether or not a geothermal heat pump it is a good investment with a short enough payoff time. Many factors influence the impact of energy actions and what is a good investment for one cooperative might not be a good investment for another. The Energy Advisors expressed concerns regarding insufficient knowledge about energy actions:

"I have a feeling that what we lack knowledge of is the impact of different actions. I have a feeling that it is very theoretical, and very poorly studied in the field. You see so many different numbers. Just check different energy advice websites and you will find different numbers for pay-off times for different actions."

With a lack of actual examples to build advice on, it is of course difficult to know which actions are suitable for which cooperatives. Since independent providers of energy advise, such as the municipal energy advisors, do not implement energy actions themselves they have to rely on other sources of data on the impact of such actions. Ironically, the contractors implementing energy actions, which are less trusted by housing cooperatives, may be the stakeholders with greatest access to data on impact of the actions, and consequently they should be able to provide the highest quality advice.

\section{Timing of Advice}

There might be times that are better than others for promoting energy improvement work and supporting housing cooperatives in turning advice into action. The 
Energy Advisors reported that housing cooperatives are particularly inclined to get in touch with the energy advice service between February and April, after having received the energy bill for the Winter months.

Budgeting for energy is difficult since the costs depend on the outdoor temperature and constantly changing energy prices. This may result in unpleasant surprises, particularly for new and inexperienced boards. At the same time, it may provide an opportunity for engaging with housing cooperatives around energy issues. Unusually high energy bills might, at least temporarily, make energy issues more important and urgent to deal with for housing cooperatives.

\section{Building Management}

To act on advice and carry out energy improvement work, as well as much other work required to run a housing cooperative, cooperatives need external help. One type of service that housing cooperatives often hire professionals to carry out is building management. This type of building management is, however, very different from the facilities management of office buildings studied for example in [10], which focuses on energy optimisations. Typically, building managers help housing cooperatives with tasks such as replacing broken light bulbs and changing nametags on doors when residents move. The work can also include very basic energy related services, such as check-ups of heating and ventilation systems.

\section{Housing Cooperative Expectations}

In addition to basic building management services, Building Management Company BM1 and the Housing Cooperative Organisation offer energy management services, with more active monitoring and control of for example heating systems, but they expressed that these are not services that housing cooperatives expect of building management and cooperatives rarely ask for them.

With such energy management services, building managers aim to take greater responsibility for energy use related to building management, but it appears to be difficult to convince housing cooperatives to pay for these services or even consider them as part of building management. The cooperatives' expectations are likely based on what services they are used to, and traditional building management services provide different values than energy services. Services such as replacing lightbulbs and changing nametags are tasks that, if not promptly carried out, people would complain about to the housing cooperative board. The benefits of energy services are often less immediate. Energy services may result in reduced energy costs in the future, but such results are uncertain.

\section{Poor Quality of Basic Services}

While basic building management services may not be related to significant improvements in energy efficiency of the buildings, checking up on energy and ventilation systems can nevertheless be important for maintaining current energy performance levels. However, stakeholders who were not energy managers questioned the quality of basic building management services. The Energy Advisors, who often visited housing cooperatives for energy audits, suspected that building management companies are not always thorough in their controls:

"...I have a feeling that they only go down there and cross it off in the protocol and leave, because the layer of dust on the temperature meters and other... is usually pretty thick. I think this is poorly managed, unfortunately."

This was confirmed by the Energy Provider who saw a relation between high heating costs and mismanaged energy systems. A concrete example of such neglect comes from one of the cooperatives we worked with: the cooperative's heat pump was not working for three years without the building management company, or anyone else, noticing. When housing cooperatives do not even receive decent quality of basic services they do pay for, it is understandable that it is challenging to persuade them to pay for additional energy services. But with a lack of energy knowledge, it might be difficult for a housing cooperative to detect if a company is doing a poor job.

One way for building management companies to prove the quality of their work could be through open energy data. Building Management Company BM1 and BM2 expressed that they were willing to use a tool with open energy data to document energy improvement actions they carry out. However, BM1 pointed out a risk of other people undoing the positive effects of their work; if a housing cooperative adjusts previously optimised temperature settings the energy use might increase. It is difficult for companies to have full control of energy systems placed in the basements of housing cooperatives, and the risk of energy improvement work being undone by people in the building exists no matter if the work is registered in an app or not. At the same time, if registering actions comes with a risk of companies appearing to do a poor job, it may incentivise companies to discuss responsibilities for the energy systems with housing cooperatives and reduce unintended increases of energy use.

\section{Long-Term Building Maintenance}

In addition to regular building management, housing cooperatives are required by law to plan and set aside money for long-term maintenance of their buildings. These plans typically cover the maintenance needs and costs for the next 30 years. The Maintenance Planning Consultancy supports housing cooperatives in creating and updating maintenance plans. In addition, they provide a digital tool that supports and documents the planning process and cost calculations. The tool does not include energy aspects, but the consultancy saw opportunities in integrating energy information in the digital maintenance plans.

Long-term maintenance influences a building's energy use, and when planning for larger renovations, such as renovations of facades or roofs, there are often benefits in 
coordinating these with energy improvements. Furthermore, since some energy investments, such as installations of heat pumps, are costly and the pay-off time is long, they need to be planned for with a similar time frame as much maintenance work. Although energy investments may not strictly count as necessary maintenance, there are still important overlaps between the two processes that could be utilised for supporting energy work.

\section{New Energy Services and Support}

To address the lack of energy improvement work in housing cooperatives and the challenges of turning advice into action, new initiatives have been formed both nationally and locally.

\section{Target-Driven Energy Management}

One new type of service that is being developed is targetdriven energy management contracts. Many stakeholders are involved in the initiative, including the Energy Advisors, Building Management Company BM1, the Local Energy Initiative and the Housing Cooperative Organisation. The idea of the contract is that a housing cooperative and their contracted building management company together set goals for improved energy performance of the cooperative. The building management company commits to do the necessary work over a number of years and the company and the cooperative split the savings from the reduced energy costs when the goal is achieved. The Local Energy Initiative presented the service as: "simple and transparent for housing cooperatives" and "safe with serious contractors".

Since the service is a collaboration between building management companies and independent organisations, such as the Energy Advisors and the Local Energy Initiative, this may increase housing cooperatives' trust in the participating companies. Furthermore, the contracts clearly connect commitments of building management companies with expected results, which increases the transparency of building management work. This could possibly be combined with open energy data and become a way of collecting information on the impact of different energy actions. The Energy Advisors suggested that sharing information about the energy improvement work in a tool such as our energy app could be regulated in the contracts. That would increase the number of documented actions and provide more cases to learn from.

\section{Local Energy Projects}

In addition to target-driven energy management, the Local Energy Initiative carries out other projects that support housing cooperatives with practicalities of implementing specific energy improvements. The projects promote six different energy improvement actions that range from rather simple (e.g. appointing an energy manager among the members) to more complicated (e.g. installing technology for local production of renewable energy). The support is mainly provided through meetings where housing cooperatives receive information about the different energy improvement projects, share experiences of completed energy improvements, and get in touch with companies providing relevant energy services and technologies. While costs and potential savings are central when energy actions are discussed in these meetings, the Local Energy Initiative stressed that environmental concern is an important driver:

"We have to reduce [carbon emissions]. That's why we're doing this, not only for the sake of costs".

Costs were highlighted by many stakeholders as central when discussing energy actions, but from our work with housing cooperatives we know that environmental concern is an important reason for some people to engage in energy management in their cooperatives. Furthermore, energy work might be initiated for reasons of addressing perceived discomfort related to indoor temperatures or ventilation, rather than as a way of reducing costs.

Although the Local Energy Initiative would have liked more focus on environmental benefits, they appreciated that the energy app we developed allows cooperatives to learn from each other's energy work, and they have promoted the app among the cooperatives in the neighbourhood. To further support the work of the initiative, they would like possibilities to overview and follow up on how the cooperatives are progressing with the specific energy improvement actions they have committed to.

\section{DESIGN OPPORTUNITIES FOR SUPPORTING STAKEHOLDER ENGAGEMENT}

From our work with housing cooperative stakeholders we have identified a number of design opportunities for interactive systems and open energy data to support energy improvement work. These include both new opportunities to directly support housing cooperatives, in line with our initial focus, but also opportunities for supporting other stakeholders that influence housing cooperative energy management. In this section, we concretise these opportunities and discuss how design sensitivities change when moving from only considering housing cooperatives as users of energy tools, to considering other stakeholders as potential users.

\section{Improving Quality and Effectiveness of Energy Advice}

One challenge with providing energy advice to housing cooperatives is that advice from stakeholders that are not trusted may be perceived with scepticism, while independent advisors may not have access to as good data as companies that implement energy actions. Opening up energy data and sharing information about energy actions allows for creating overviews of different actions and their impact on energy use based on actual cases, which in the long run could improve the quality of energy advice. It is, however, complicated to measure energy impact, as many factors other than energy actions influence energy use. Furthermore, since this type of data is registered by people, possibly working for companies caring about their reputation, there is a risk that only successful 
implementations of actions are registered or that unsuccessful implementations are removed. Hence, we believe that it is difficult to design automatic overviews of energy impact based on this type of data, and we suggest that the design rather should provide an interface for independent energy experts to identify interesting cases and explore factors influencing the impact of energy actions in these cases.

Having access to information about housing cooperatives and their energy use may also support energy advisors, and other stakeholders providing energy advice, to target their advice at cooperatives with high energy reduction potential or with buildings suitable for specific energy improvements. Similarly, an overview of the local housing cooperatives and their current energy status could help the Local Energy Initiative to direct their efforts and limited resources at those cooperatives that need it the most. This would require a different focus compared to our design of the energy app, which highlights good examples for other housing cooperatives to learn from. In addition to making it easy to find cooperatives with low energy use and those that have implemented energy actions, it would be useful to easily identify cooperatives that have not taken action or where the energy use has increased. To not discourage housing cooperatives with poor energy performance from sharing their energy data, the design of such features would have to be carefully implemented. By focussing the design on changes over time, stakeholders could also be supported in identifying housing cooperatives with sudden increases in energy use (and related costs), to find cooperatives where energy issues are perceived as more urgent.

\section{Supporting Trust in Service Providers and New Energy Services}

Open energy data connected to energy services and specific energy improvement actions performed by different stakeholders could be a way for these stakeholders to prove the quality of their services and that they can be trusted. However, since many housing cooperatives do not buy specific energy services, but only ask for basic building management services, it would be important to show the effects also of good quality basic services. This means that the design, in addition to highlighting reduction of energy use of specific energy improvement actions, should make it clear that lack of increase of energy use (i.e. maintaining current levels) can be a result of good quality basic building management services.

To move from basic services to new energy services, such as the target-driven energy management described in an earlier section, housing cooperatives need to be convinced to try these services. Open energy data could contribute to transparency by showing the actual energy impact of the service among those cooperatives that have tried the targetdriven contract. This may lower the threshold for others to try the service and could be a way for building management companies to show the value of energy services to cooperatives that only ask for basic building management services. When designing for such support, it is important to show the impact of the service as a whole and not only evaluating individual actions. While we previously aimed at supporting housing cooperatives in learning about specific energy improvement actions they may be interested in, a focus on services would need a design that also conveys the aggregated impact of the many actions that can be part of a service. For target-driven energy management, the impact can also be visualised in relation to the energy reduction goal which is set as part of the contract.

If the building management companies, which regularly work with housing cooperatives and maintain relations over many years, would use the energy app as part of their work, they would also provide continuity of the app in a housing cooperative. In this way, losing housing cooperative app users (e.g. when people move) does not necessarily mean that the app will be forgotten in a cooperative; there would still be app users connected to the cooperative through the building managers.

\section{Integrating Energy in Long-Term Planning and Support} For energy improvements that require large investments, it is important with a long-term perspective on the investments. This can, however, be challenging in a housing cooperative where the members frequently move. It may therefore be beneficial to integrate energy work in processes of maintenance planning, where long-term thinking (of up to 30 years ahead) already is required. Here, a design focussing on past energy use and actions taken could complement a future-oriented planning perspective. More specifically, maintenance planning tools can highlight opportunities for combining regular renovations with energy improvements. Open energy data can support this by showing how energy improvements actions previously have been connected to renovations by other housing cooperatives. In addition, since energy improvements often result in reduced energy costs, estimated savings could also be included in maintenance planning tools which currently focus only on costs.

Although cost is an important aspect of energy work, there are reasons to not focus interactive systems solely on cost aspects. Other values, such as increased comfort, are important for getting the cooperative members' support for taking energy improvements actions. Furthermore, environmental concern is a reason for why both the Local Energy Initiative and many housing cooperatives engage in energy improvement work. It may therefore be useful to highlight not only monetary savings but also other benefits of these actions. Data on carbon emissions for electricity and district heating could be used as a basis for showing the environmental impact of different energy actions. In line with our original design that focused on sharing experiences, we could also prompt people to share experiences of "problems" that were solved by energy improvements, such as complaints about drafts or uneven 
indoor temperatures, and put these forward as potential benefits of energy improvement actions.

\section{DISCUSSION}

Involving different types of stakeholders in Sustainable $\mathrm{HCI}$ research comes with new opportunities as well as challenges. In this section, we draw from the findings of the housing cooperative case to discuss more general design implications for Sustainable HCI research exploring stakeholder engagement in resource-intensive practices.

\section{Which Stakeholders and Which Practices?}

When we studied energy management practices and explored how they potentially could change to better support energy improvement work, we identified many efforts other than technology aiming to support such change. With a practice perspective, interactive systems naturally get a less central role in studies and it becomes necessary to recognise other elements of these practices [27]. This has implications also for design. The design opportunities we identified were all aiming to support existing or emerging stakeholder activities related to housing cooperative energy management. In line with Toyama [39], who stress the limitations of technology in creating social change, we regard technology mainly as an amplifier of other activities. This is not new to Sustainable $\mathrm{HCI}$, where technology has been explored for example as amplifiers of professional energy management [10] or of community efforts to support households in eco-efficient retrofitting [24].

To identify opportunities for amplification it may be useful to study bundles or complexes of practices [34] that are linked to and influence each other, and that are performed by various stakeholders. This would require studies not only of the consumption side of practices, such as cooking, shopping or commuting, but also of practices related to for example production, distribution or management of resources. This can, however, easily become an overwhelming number of practices. In our work, we focused on practices that were closely linked to housing cooperative management and where the stakeholders had direct contact with housing cooperatives. This has left out stakeholders such as policy makers, who influence energy improvement work for example through subsidies and energy regulations. While it is not possible to engage with everyone, it might be difficult to know beforehand which stakeholders are most relevant. From the stakeholder meetings we were involved in, we continuously increased our knowledge of relevant practices and heard about or got in touch with additional stakeholders that we did not previously consider in relation to energy management. One example, which we believe provides an interesting direction for future work concerned with energy improvements, is stakeholders involved in financial aspects of energy improvement work, such as banks offering loans for "green investments".
Another challenge of stakeholder engagement is that not all stakeholders are equally accessible or interested taking part in research. In our case, having an app that was already in use by housing cooperatives helped us catching the interest of stakeholders who had housing cooperatives as customers. However, having an up-and-running app comes with a risk of the design being perceived as "finished", and a more conceptual design might have sparked different types of ideas. Nevertheless, the app was still helpful for discussing open energy data and energy management with the stakeholders. In addition, it was useful for communicating the results from the first stages of our research, and communicating research has been stressed as another important reason for Sustainable HCI to engage more with various types of stakeholders [29].

\section{Interaction Over Different Time Scales}

One of the main challenges for our energy app, when considering it primarily as a tool to be used by housing cooperatives, was how to support the often slow and longterm work of housing cooperative energy management when the people in charge may have only a short-term and sporadic engagement in the work. One option could be to redesign our energy app with the goal of encouraging housing cooperatives to increase their time spent on energy management and to use the energy app more frequently to support this work. However, if we consider other stakeholders, such as building managers, as potential users of our app, we could design the energy app to support different engagement over time for different stakeholders: building managers can use the app as part of their professional practices, and provide continuity over time, while housing cooperatives can have a more sporadic use.

Similarly, professionals involved in other resourceintensive practices, such as food practices or transportation, could provide continuity of interactive systems that may only occasionally be interesting for resource users. Thus, we suggest that designing systems to allow for occasional use by those who traditionally may be regarded as primary users may in some cases be more productive than aiming to integrate technology into resource users' everyday life. It has indeed proven challenging to keep users engaged in resource use through interactive systems: many studies report a declining interaction with the systems over time [28]. At the same time, it has been argued that Sustainable HCI should consider longer time scales [35]. To consider longer time scales in Sustainable HCI, we believe it is necessary to also consider alternative forms of engagement than continuous engagement in everyday life.

Another time perspective on interaction, different from designing for everyday life, is to design for rare events that can impact the formation of new practices. It has been suggested that Sustainable HCI should explore reconfigurations of unsustainable practices by creating "crises of routine" [20]. However, such crises also occur naturally all the time and could provide opportunities for 
design interventions. Examples from our case include when a housing cooperative change their board, when they get the energy bill after a cold winter (and may be more open to addressing energy issues), or when they plan for larger renovations that can be combined with energy improvement work. While a tool such as our energy app could be designed to better support housing cooperatives at times of "crises of routine", including additional stakeholders as users of the tool provides different design opportunities. Interactive systems could, for example, support energy advisors or local energy initiatives to actively approach cooperatives at appropriate times. We believe that this approach could be further explored for other resourceintensive practices in Sustainable HCI.

\section{Supporting Shared Responsibility}

An important reason for us to include additional stakeholders in our study was to question assumptions of consumer responsibility for resource use and to explore responsibilities of other stakeholders. While interactive systems can be used for example to empower people by supporting them in reaching out to powerful stakeholders [28], just focussing on empowerment still implies that the responsibility to change lies with the resource user. Other stakeholders may need support to more actively share responsibility for resource use. Parallels can be drawn to technologies supporting civic engagement, where Harding et al. [15] argue that a too strong focus on citizen empowerment is limiting the use and value of such technologies. Instead, they suggest to work with both citizens and authorities with the aim of facilitating trust between the two.

In our case, the projects by the Local Energy Initiative and the new forms of target-driven energy management are examples where stakeholders actively wanted to take responsibility for resource use, and where we believe interactive systems could support their engagement with housing cooperatives by facilitating trust. In these cases, and possibly for other types of services or initiatives aiming to contribute to more sustainable use of resources, technology can contribute to transparency and trust for example by making responsibilities of different stakeholders explicit, and by holding stakeholders accountable based on actual outcomes of their work.

Sharing responsibility for resource use between different stakeholders is, however, not always feasible. People may, for example, not expect stakeholders such as companies or governments to share responsibility for energy-related matters that are considered personal [37]. Conflicts of interest can also make it difficult for stakeholders to share responsibility. The Energy Provider in our study appeared to want to take more responsibility for changing the way energy is used by providing housing cooperatives with energy advice. However, their business models conflicted with sustainability goals, which made it difficult for housing cooperatives to trust their advice. Similar challenges of lack of trust in energy companies, potentially affecting the adoption of new energy services, are reported in other studies [1,30]. It is therefore important to acknowledge conflicts that may cause distrust. In such cases it may not be possible to share responsibility for resource use without first addressing underlying conflicts.

We recognise that combining different stakeholder perspectives and supporting shared responsibility between stakeholders is challenging. For housing cooperative energy management, we can for example see risks of attending too much to the needs of professional stakeholders in the design of interactive systems. If energy professionals are engaged as users of our energy app and contribute with content, they might appropriate it to their needs and use a professional language that excludes many housing cooperative users. However, we experienced that moving back and forth between perspectives of different stakeholders was helpful for identifying risks and potential conflicts of interest.

\section{CONCLUSION}

Sustainable HCI has for many years stressed the need for engaging stakeholders other than individuals $[7,17,19,28]$, but studies of involvement of such stakeholders in resource use are still limited. In this paper we presented a study of stakeholder engagement in housing cooperative energy improvement work, and design opportunities to support such engagement for example by contributing to improved quality and effectiveness of energy advice, and by supporting trust in service providers and new types of energy services. Furthermore, we discussed more general design implications for Sustainable HCI research aiming to support stakeholder engagement in resource-intensive practices. We argue, in line with Toyama [39], that when the goal is to influence social practices, interactive systems can mainly amplify (existing) social activities. In order to identify such activities, we suggest that Sustainable HCI should explore bundles or complexes of practices that are performed by various stakeholders. Moreover, we suggest that diverse stakeholder engagement in resource use can open up for new ways of addressing the tension between long-term sustainability ambitions and short-term interaction with interactive systems. Finally, we see a potential in designing for shared responsibility for resource use, where supporting trust between stakeholders is central.

Numerous HCI studies have already thoroughly investigated resource use from a consumer perspective, and those results could be built on by exploring additional stakeholder engagement. Although this paper mainly focuses on energy use, we believe the design implications are relevant for addressing other types of resource use since sustainability issues are inherently complex and span over many stakeholders.

\section{ACKNOWLEDGMENTS}

This research was funded by the EU FP7 programme through the project CIVIS (no 608774) and the Swedish Energy Agency. 


\section{REFERENCES}

1. Alper T. Alan, Enrico Costanza, Sarvapali D. Ramchurn, Joel Fischer, Tom Rodden, and Nicholas R. Jennings. 2016. Tariff Agent: Interacting with a Future Smart Energy System at Home. ACM Transactions on Computer-Human Interaction 23, 4: 1-28. https://doi.org/10.1145/2943770

2. Bharathan Balaji, Jason Koh, Nadir Weibel, and Yuvraj Agarwal. 2016. Genie: A longitudinal study comparing physical and software thermostats in office buildings. In UbiComp 2016 - Proceedings of the 2016 ACM International Joint Conference on Pervasive and Ubiquitous Computing, 1200-1211. https://doi.org/10.1145/2971648.2971719

3. Ben D. Bedwell, Enrico Costanza, and Michael Jewell. 2016. Understanding Energy Consumption at Work: Learning from Arrow Hill. In Proceedings of the 19th ACM Conference on Computer-Supported Cooperative Work \& Social Computing (CSCW'16), 1337-1348. https://doi.org/10.1145/2818048.2819993

4. Victoria Bellotti, Alexander Ambard, Daniel Turner, Christina Gossmann, Kamila Demková, and John M. Carroll. 2015. A Muddle of Models of Motivation For Using Peer-to-Peer Economy Systems. In Proceedings of the 33rd Annual ACM Conference on Human Factors in Computing Systems (CHI '15), 1085-1094. https://doi.org/10.1145/2702123.2702272

5. Hrönn Brynjarsdottir, Maria Håkansson, James Pierce, Eric Baumer, Carl Disalvo, and Phoebe Sengers. 2012. Sustainably Unpersuaded: How Persuasion Narrows Our Vision of Sustainability. In Proceedings of the SIGCHI Conference on Human Factors in Computing Systems (CHI '12), 947-956. Retrieved November 12, 2014 from http://dl.acm.org/citation.cfm?id=2208539

6. Adrian K. Clear, Sam Mitchell Finnigan, Patrick Olivier, and Rob Comber. 2017. "I'd Want to Burn the Data or at Least Nobble the Numbers": Towards Datamediated Building Management for Comfort and Energy Use. In Proceedings of the 2017 ACM Conference on Computer Supported Cooperative Work and Social Computing (CSCW'17), 2448-2461.

7. Adrian K. Clear, Kirsti O’Neill, Adrian Friday, and Mike Hazas. 2016. Bearing an Open "Pandora's Box": HCI for Reconciling Everyday Food and Sustainability. ACM Transactions on Computer-Human Interaction 23, 5: 1-25. https://doi.org/10.1145/2970817

8. Carl DiSalvo, Phoebe Sengers, and Hrönn Brynjarsdóttir. 2010. Mapping the landscape of sustainable HCI. In Proceedings of the SIGCHI Conference on Human Factors in Computing Systems (CHI '10), 1975-1984. https://doi.org/10.1145/1753326.1753625

9. David Evans. 2011. Blaming the consumer - once again: the social and material contexts of everyday food waste practices in some English households. Critical Public Health 21, 4: 429-440. https://doi.org/10.1080/09581596.2011.608797

10. S. Mitchell Finnigan, A. K. Clear, G. Farr-Wharton, K. Ladha, and R. Comber. 2017. Augmenting Audits: Exploring the Role of Sensor Toolkits in Sustainable Buildings Management. Proceedings of the ACM on Interactive, Mobile, Wearable and Ubiquitous Technologies 1, 2: 1-19. https://doi.org/10.1145/3090075

11. Joel E. Fischer, Enrico Costanza, Sarvapali D. Ramchurn, James Colley, and Tom Rodden. 2014. Energy Advisors at Work: Charity Work Practices to Support People in Fuel Poverty. In Proceedings of the 2014 ACM International Joint Conference on Pervasive and Ubiquitous Computing (UbiComp '14), 447-458. https://doi.org/10.1145/2632048.2636081

12. Joel E. Fischer, Andy Crabtree, Tom Rodden, James A. Colley, Enrico Costanza, Michael O. Jewell, and Sarvapali D. Ramchurn. 2016. "Just Whack It on Until It Gets Hot": Working with IoT Data in the Home. In Proceedings of the 2016 CHI Conference on Human Factors in Computing Systems (CHI '16), 5933-5944. https://doi.org/10.1145/2858036.2858518

13. Eva Ganglbauer, Geraldine Fitzpatrick, Özge Subasi, and Florian Güldenpfennig. 2014. Think Globally, Act Locally: A Case Study of a Free Food Sharing Community and Social Networking. In Proceedings of the 17th ACM conference on Computer supported cooperative work \& social computing (CSCW'14), 911-921. https://doi.org/10.1145/2531602.2531664

14. William Gaver, Mike Michael, Tobie Kerridge, Alex Wilkie, Andy Boucher, Liliana Ovalle, and Matthew Plummer-Fernandez. 2015. Energy Babble: Mixing Environmentally-Oriented Internet Content to Engage Community Groups. In Proceedings of the 33rd Annual ACM Conference on Human Factors in Computing Systems (CHI '15), 1115-1124.

15. Mike Harding, Bran Knowles, Nigel Davies, and Mark Rouncefield. 2015. HCI, Civic Engagement \& Trust. In Proceedings of the 33rd Annual ACM Conference on Human Factors in Computing Systems (CHI '15), 2833-2842. https://doi.org/10.1145/2702123.2702255

16. Hanna Hasselqvist, Cristian Bogdan, and Filip Kis. 2016. Linking Data to Action: Designing for Amateur Energy Management. In Proceedings of the 2016 ACM Conference on Designing Interactive Systems (DIS '16), 473-483. https://doi.org/10.1145/2901790.2901837

17. Hanna Hasselqvist, Mia Hesselgren, and Cristian Bogdan. 2016. Challenging the Car Norm: Opportunities for ICT to Support Sustainable Transportation Practices. In Proceedings of the 2016 CHI Conference on Human Factors in Computing 
Systems (CHI'16), 1300-1311.

https://doi.org/10.1145/2858036.2858468

18. Yen-Chia Hsu, Paul Dille, Jennifer Cross, Beatrice Dias, Randy Sargent, and Illah Nourbakhsh. 2017. Community-Empowered Air Quality Monitoring System. In Proceedings of the 2017 CHI Conference on Human Factors in Computing Systems (CHI '17), 1607-1619. https://doi.org/10.1145/3025453.3025853

19. Maria Håkansson and Phoebe Sengers. 2014. No Easy Compromise: Sustainability and the Dilemmas and Dynamics of Change. In Proceedings of the 2014 conference on Designing interactive systems (DIS '14), 1025-1034. https://doi.org/10.1145/2598510.2598569

20. Lenneke Kuijer, Annelise De Jong, and Daan Van Eijk. 2013. Practices as a Unit of Design: An Exploration of Theoretical Guidelines in a Study on Bathing. ACM Transactions on Computer-Human Interaction 20, 4: 1-22. https://doi.org/10.1145/2493382

21. Pascal Lessel, Maximilian Altmeyer, and Antonio Krüger. 2015. Analysis of Recycling Capabilities of Individuals and Crowds to Encourage and Educate People to Separate Their Garbage Playfully. In Proceedings of the 33rd Annual ACM Conference on Human Factors in Computing Systems (CHI '15), 1095-1104. https://doi.org/10.1145/2702123.2702309

22. Ann Light and Jo Briggs. 2017. Crowdfunding platforms and the design of paying publics. In Proceedings of the 2017 CHI Conference on Human Factors in Computing Systems (CHI '17), 797-809. https://doi.org/10.1145/3025453.3025979

23. Jennifer Mankoff, Eli Blevis, Alan Borning, Batya Friedman, Susan R. Fussell, Jay Hasbrouck, Phoebe Sengers, and Allison Woodruff. 2007. Environmental sustainability and interaction. In CHI '07 Extended Abstracts on Human Factors in Computing Systems, 2121-2124.

https://doi.org/http://doi.acm.org/10.1145/1240866.124 0963

24. Elaine Massung, Daniel Schien, and Chris Preist. 2014. Beyond behavior change: Household retrofitting and ICT. In 2nd International Conference on ICT for Sustainability (ICT4S 2014), 132-139. https://doi.org/10.2991/ict4s-14.2014.16

25. Matthew Louis Mauriello, Leyla Norooz, and Jon E. Froehlich. 2015. Understanding the Role of Thermography in Energy Auditing: Current Practices and the Potential for Automated Solutions. In Proceedings of the 33rd Annual ACM Conference on Human Factors in Computing Systems (CHI '15), 1993-2002. https://doi.org/10.1145/2702123.2702528

26. Matthew Louis Mauriello, Manaswi Saha, Erica Brown, and Jon E. Froehlich. 2017. Exploring Novice Approaches to Smartphone-based Thermographic Energy Auditing. In Proceedings of the 2017 CHI
Conference on Human Factors in Computing Systems (CHI'17), 1768-1780.

https://doi.org/10.1145/3025453.3025471

27. James Pierce, Yolande Strengers, Phoebe Sengers, and Susanne Bødker. 2013. Introduction to the special issue on practice-oriented approaches to sustainable HCI. ACM Transactions on Computer-Human Interaction 20, 4: 1-8. https://doi.org/10.1145/2509404.2494260

28. Sebastian Prost, Elke Mattheiss, and Manfred Tscheligi. 2015. From Awareness to Empowerment: Using Design Fiction to Explore Paths towards a Sustainable Energy Future. In Proceedings of the 18th ACM Conference on Computer Supported Cooperative Work \& Social Computing (CSCW'15), 1649-1658. https://doi.org/10.1145/2675133.2675281

29. Christian Remy and Elaine M. Huang. 2018. Communicating SHCI research to practitioners and stakeholders. In Digital Technology and Sustainability: Engaging the Paradox, Mike Hazas and Lisa Nathan (eds.). Routledge.

30. Tom A Rodden, Joel E Fischer, Nadia Pantidi, Khaled Bachour, and Stuart Moran. 2013. At home with agents: Exploring attitudes towards future smart energy infrastructures. In Proceedings of the SIGCHI Conference on Human Factors in Computing Systems (CHI '13), 1173-1182. https://doi.org/10.1145/2470654.2466152

31. Marlyne Sahakian and Harold Wilhite. 2014. Making practice theory practicable: Towards more sustainable forms of consumption. Journal of Consumer Culture 14, 1:25-44. https://doi.org/10.1177/1469540513505607

32. Elizabeth Shove. 2010. Beyond the ABC: climate change policy and theories of social change. Environment and Planning A 42, 6: 1273-1285. https://doi.org/10.1068/a42282

33. Elizabeth Shove and Mika Pantzar. 2007. Recruitment and Reproduction: The Careers and Carriers of Digital Photography and Floorball. Human Affairs 17, 2: 154167. https://doi.org/10.2478/v10023-007-0014-9

34. Elizabeth Shove, Mika Pantzar, and Matt Watson. 2012. The Dynamics of Social Practice: Everyday Life and how it Changes. SAGE Publications. Retrieved May 14, 2015 from https://books.google.com/books?hl=en\&lr=\&id=LILf3b9P-AC\&pgis $=1$

35. M. Six Silberman, Lisa Nathan, Bran Knowles, Roy Bendor, Adrian Clear, Maria Håkansson, Tawanna Dillahunt, and Jennifer Mankoff. 2014. Next Steps for Sustainable HCI. Interactions 5: 66-69. https://doi.org/10.1145/2651820

36. Yolande Strengers. 2011. Negotiating everyday life: The role of energy and water consumption feedback. 
Journal of Consumer Culture 11, 3: 319-338. https://doi.org/10.1177/1469540511417994

37. Yolande Strengers. 2012. Peak electricity demand and social practice theories: Reframing the role of change agents in the energy sector. Energy Policy 44: 226234. https://doi.org/10.1016/j.enpol.2012.01.046
38. Yolande Strengers. 2014. Smart Energy in Everyday Life: Are You Designing for Resource Man? Interactions 21, 4: 24-31.

39. Kentaro Toyama. 2015. Geek Heresy. PublicAffairs. 